\title{
Micro cogeneration with a price-variable heat storage switch
}

\author{
G. Kaestle \\ Consultant, Karlsruhe, Germany
}

\begin{abstract}
Operating modes of combined heat and power (CHP) units are: heat driven, power driven and grid driven. CHP mini blocks are also known as "magic boilers" or as electricity generating heating. Several techniques have been developed for optimising the economic dispatch of the CHP-system including the cogeneration unit, a heat buffer, and a peak burner, as well as thermal and electrical loads. This paper will propose a simple and easy to implement method in order to benefit from the different modi operandi. Ordered by contribution margin, the storage level of the heat buffer switches the CHP-system between the modes off, grid or power driven, heat driven, and full load. A daytime variable but static price profile is saved in the system control. It dynamically contracts or expands the threshold levels of the storage switch. Finally, the results of a simulation are presented in which a settlement of $80 \mathrm{CHP}$-equipped households is turned into a net electricity exporter, thus substituting coal based medium load power by natural gas.
\end{abstract}

Keywords: cogeneration, heat storage, microCHP, power dispatch, price profile.

\section{Motivation}

The sales numbers of the Honda Ecowill in Japan, as well as those of Senertec Dachs in Germany, are showing that micro cogeneration systems are beginning to move out of their niche market. In the UK two Stirling based designs for domestic cogeneration - Microgen and Whispergen - are competing in field tests for being the first one to hit mass production. The question is whether these tiny electricity generators should operate only to meet the local heat demand, or 
whether they should be able to perform a sophisticated production scheme in order to deliver economic benefits to the energy system $[1,2]$.

\section{Micro cogeneration}

The combined production of heat and power (CHP) promises an increase in fuel efficiency. Small units also known as 'magic boilers' serve as electricity generating heating units in buildings. MicroCHP benefits from edifice integration as no district heating grid is needed. Nevertheless, the higher capital expenditure compared to usual heating systems prevents widespread installation.

\subsection{Combined heat and power technologies}

Small CHP modules are typically integrated into a heating installation along with extra components. First, an auxiliary burner assists in meeting the peak heat demand during winter. Then, a heat storage unit - usually a hot water tank minimises the thermal cycling of the $\mu \mathrm{CHP}$ unit and temporally decouples the supply of heat and electricity. The power balance is settled via the link to the low voltage (LV) grid, as displayed in Figure 1.

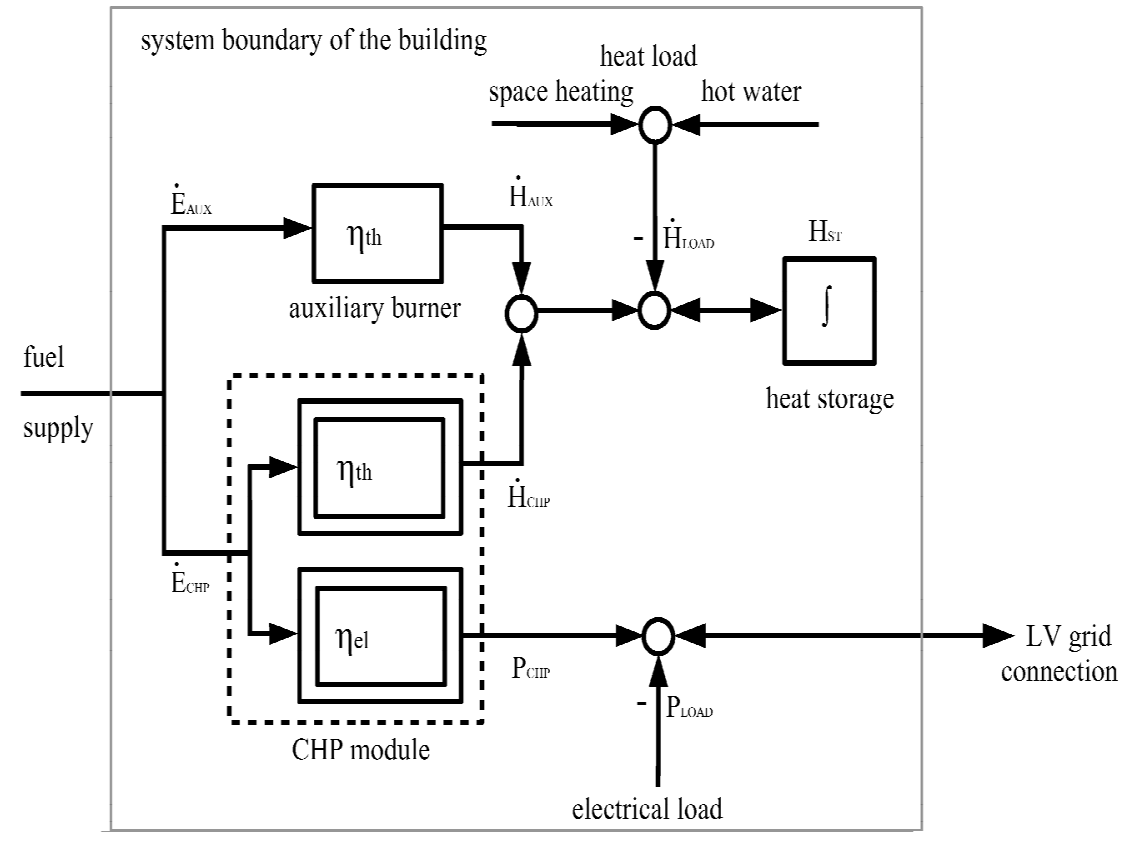

Figure 1: $\quad$ Energy flow diagram of a microCHP installation.

Several conversion technologies Pehnt et al [3] have been developed to provide electricity and heat from fossil fuels. They are powered by heating oil, or 
more commonly by natural gas and propane. Recent developments incorporate the use of biofuels.

The classic design is an internal combustion engine propelling an alternator. Heat is recovered from the closed circuit cooling, the generator, and the exhaust gas. Another type is the Stirling engine where an external flame heats a sealed amount of working gas. The gas drives a power piston and is cooled down by the cold return flow of the hydronic heating. The steam engine works similarly: water evaporates by external combustion, and the steam generates power in an expander. Thermal energy is transferred to the heating system in the condenser where the vapour liquefies and is then pumped back into the steam generator.

Micro turbines derive from exhaust turbo-superchargers. Furthermore, progress in materials science has allowed the development of high speed generators. The temperature level of the exhaust gas is sufficient for process heat applications and combines well with absorption chillers. The last three CHP configurations show low emissions due to continuous combustion and minor maintenance costs because of oil free lubrication.

Fuel cells promise high efficiency, as well as marginal emissions with low maintenance requirements. They are regarded as the power system of the future, but still need research to reduce manufacturing costs and to increase durability. The fuel is burned indirectly in an electrochemical cell, thus generating a direct current. Power electronics convert it to alternating current.

Inverter based designs Mauch [4] of distributed energy resources (DER) are used not only in future cogeneration concepts with fuel cells but also in present $\mu \mathrm{CHP}$ units with thermal engines. As an electronic gear, they support power modulation without relevant efficiency losses by varying the engine's RPM. Furthermore, modules for observing the grid are integrated in order to detect any grid failures.

\subsection{Operating modes}

In addition to the production levels OFF and ON (=full throttle), power modulation enables the operator to fulfil specific production schemes within the CHP-module's individual capacity limits Pmin,i and Pmax,i.

\subsubsection{Heat driven}

In heat driven mode, unit $\mathbf{i}$ follows the local demand for heat $\mathbf{H}^{\prime} \mathbf{L O A D}, \mathbf{i}$. Therefore, with $\mathbf{s}=\boldsymbol{\eta}_{\mathrm{el}} / \boldsymbol{\eta}_{\text {th }}$ as CHP coefficient, the power output is:

$$
\mathrm{P}_{\mathrm{CHP}, \mathrm{i}}=\mathrm{Si}_{\mathrm{i}} \cdot \mathrm{H}_{\text {LOAD, } \mathrm{i}}
$$

\subsubsection{Power driven}

In power driven mode, the unit of feed-in node $\mathbf{i}$ follows the local demand for power Pload, - - thus the power output is:

$$
\mathrm{P}_{\mathrm{CHP}, \mathrm{i}}=\mathrm{P}_{\text {LOAD, }} \mathrm{i}
$$

Usually, a power driven and heat capped approach is chosen in cogeneration practise, so that no excess heat is wasted. 


$$
\mathrm{P}_{\mathrm{CHP}, \mathrm{i}}=\operatorname{Min}\left(\mathrm{P}_{\mathrm{LOAD}, \mathrm{i}} ; \mathrm{Si}_{\mathrm{i}} \cdot \mathrm{H}_{\mathrm{LOAD}, \mathrm{i}}^{\prime}\right)
$$

\subsubsection{Grid driven}

The idea of the grid driven mode is that the local grid segment detects its load condition and accordingly sets the production levels of attached energy resources. An extreme example is the micro- or minigrid with islanding abilities. Consequently, the grid driven mode is a special version of the power driven mode, where the unit $\mathbf{i}$ follows the aggregate demand for power $\Sigma$ PLOAD,i.

$$
\mathrm{P}_{\mathrm{CHP}, \mathrm{i}}=\mathrm{f}\left(\Sigma \mathrm{P}_{\text {LOAD }, \mathrm{i}}\right)
$$

\section{The heat storage switch}

The hot water storage is supposed to have a stratified loading system. So, hot water at the desired temperature is available even at low storage levels. To simplify matters, the heat buffer is regarded as plain energy storage, without needing to determine the temperature of the mass flow going in and out.

The heat buffer is used to switch between the operating modes. Depending on the heat storage level, the local control may switch between the modes full load, heat driven, power driven, grid driven, and off.

\subsection{Mode switching}

The operating modes are arranged by return on consumed fuel (see Figure 2). The thermal credit is added to the power credit and related to the cost of the fuel input. As the feed-in tariff for electricity is usually lower than the yield from avoided grid supply, the power driven mode is preferred to the heat driven. Where to put the grid driven mode is strongly dependant on the operator's view, i.e. as an owner, contractor, or utility affiliated power producer, and the compensation for grid friendly feed-in behaviour.

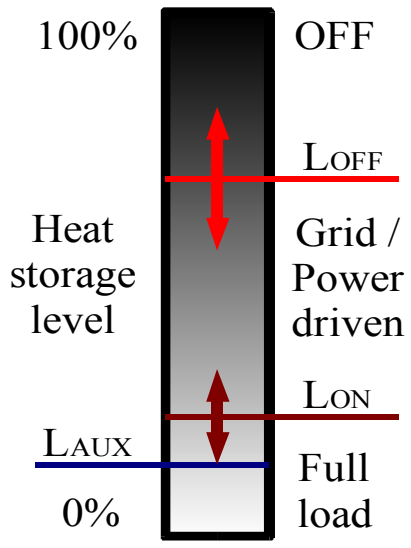

Figure 2: $\quad$ Heat storage as a switch. 
Obviously, the cogeneration unit should run at full load when the heat buffer is depleted. At the other end of the scale, the CHP mini plant switches off, as excess heat should not be wasted due to economical and ecological reasons. Within these limits, the unit is able to perform preferred generation programmes.

Nevertheless, the $\mu$ CHP unit is the building's basic heat source. Thus, it is obvious that in periods of high heat demand, such as on cold winter days, the energy level of the thermal storage is low and the power block runs at full load, assisted by the auxiliary burner. During summer, when the heat demand is rather low and determined by the domestic hot water consumption, the heat storage is often full and the power block switches off. The range between these extremities can be utilised for market adjusted power production.

\subsection{Integration of electricity prices}

The optimisation of the power dispatch aims at minimising costs or maximising the profit margin. As electricity is a commodity that is difficult to store, the value is strongly dependent on the time of its generation. Thus, it is desirable to adapt the production scheme of a CHP-plant to the pricing developments.

Bühner [5] presented an implementation of an on-line optimisation tool for distributed power systems. In the beginning of the demo project, five plants were integrated. With the available computer hardware, the mixed integer optimisation problem had to be fine-tuned, as a solution was needed within a reasonable time period. Obviously, a central control for hundreds or thousands of $\mu$ CHP-blocks cannot run extensive mixed integer programs. Therefore, an easy to use heuristic method with robust rules will be proposed in the following.

Micro cogeneration concerns the retail business of both the grid export and import side. Over-complicated products may not be accepted by the customer (e.g. Buchholz [6]).

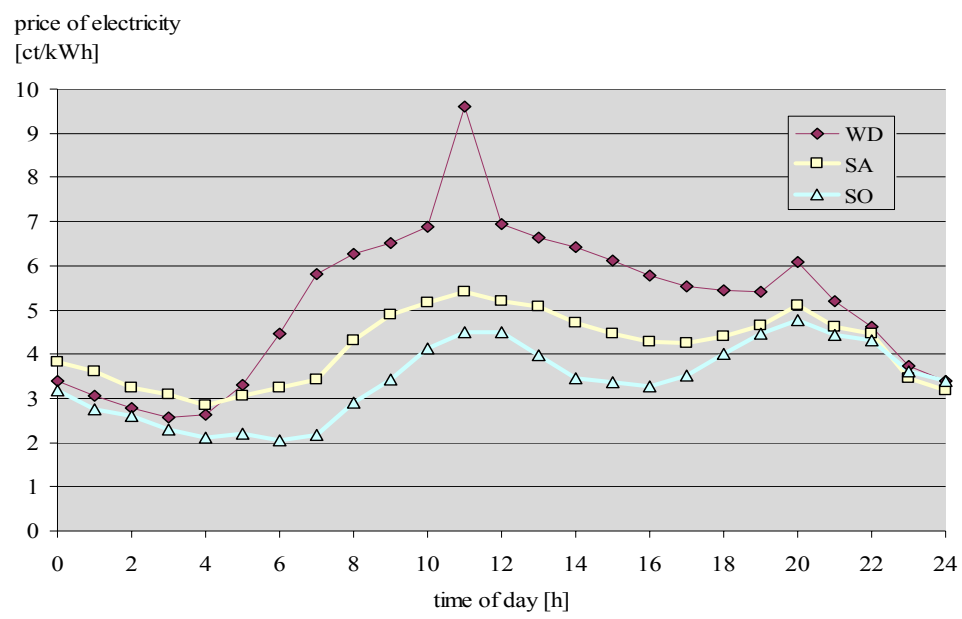

Figure 3: Average spot prices for workdays, Saturdays and Sundays (sample data from EEX, 3-18.9.2005). 
Price profiles can show various patterns. A simple one could consist of threetier time zones for low, medium and peak tariff. As the low tariff was introduced to stimulate demand during the night, a peak tariff could be useful for enhancing the feed-in during the hours around noon. A more precise profile with hourly data could also be used. If there is an on-line link available, current price signals from an energy exchange could serve as a reference. However, average price profiles will likewise satisfy, as shown in Figure 3.

Figure 2 contains three thresholds for the energy content Lon, LofF, and LAux. Below LAUX the auxiliary burner kicks in. It ensures the availability of a convenient volume of hot water. Between Lon and Loff the CHP module operates in the chosen mode, e.g. power driven. Above Loff and below Lon the control gradually reduces and accordingly elevates the unit's power output.

LaUX is a fixed value, but the other limits controlling the $\mu$ CHP can both move up and down the scale. A calculation based on the electricity to gas price ratio is useful.

$$
\mathrm{L}^{\prime}(\mathrm{t})=\operatorname{pel}(\mathrm{t}) / \operatorname{pgas}(\mathrm{t}) \cdot \mathrm{L}
$$

Rising power prices expand the thresholds and increase the working storage volume. Falling prices induce a reduced buffer capacity and limit the heat capped power production. There may be even the case (pel<pgas) when the auxiliary burner supplies the heat demand, although the cogeneration capacities are able to suffice the thermal needs.

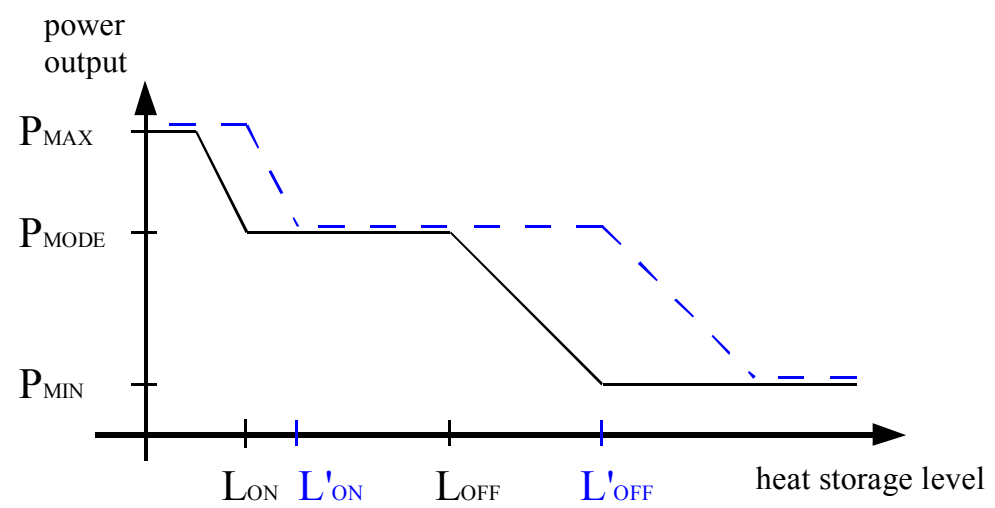

Figure 4: Switching function of the price variable heat storage switch.

The switching function is shown in Figure 4. In this way, the power production of the chosen operational mode is affected both by the local heat demand, indicated by the buffer level and the changing value of electricity, which shifts the switching thresholds. Levels L are based on lower prices, whereas levels L' emerge because of higher prices. Accordingly, Lon boosts generation during peak time hours and Loff cuts production in the nightly offpeak.

Figure 5 displays curves of the heat storage level, the $\mu \mathrm{CHP}$ module's heat production in power driven mode and of the electricity price during a summer 
week (two working days, weekend, and three working days). The output of the cogeneration unit drops when the electricity's value is low. Consequently, the further rising of the storage level stops during the night and on the weekend parts of the buffered thermal energy are consumed. If the pel-to-pgas ratio goes up, electricity will be generated, therefore storage volume for excess heat is increased. If the ratio goes down, it will be cheaper to buy electricity. Stored heat has to be used up to be ready for the next peak cycle with an empty heat buffer.
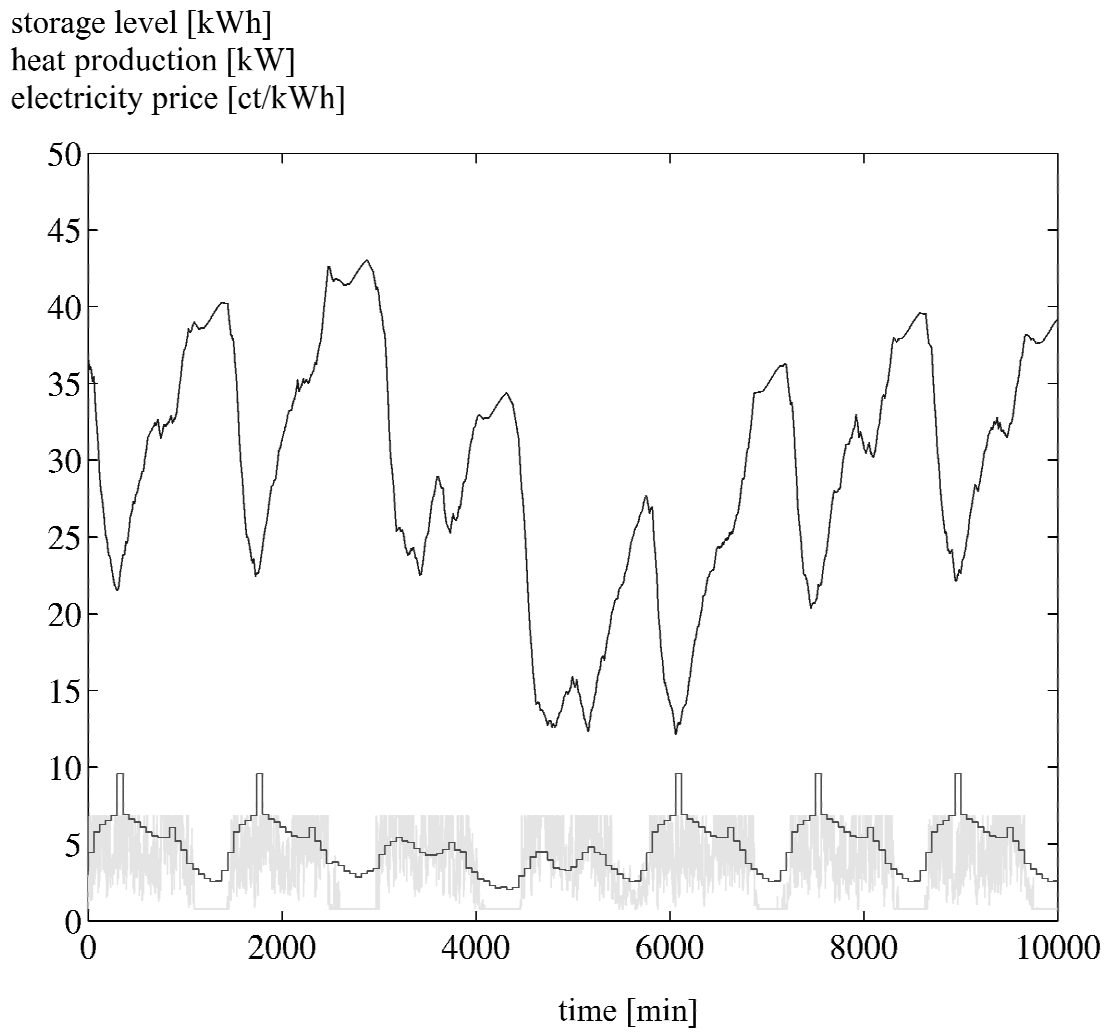

Figure 5: Diagram of storage level, heat production, and price signal.

As a result, electricity is exported to the grid at higher prices and imported at lower prices. Table 1 gives a synopsis on an example with fixed and variable storage thresholds. The figures originate from a simulation of 80 homes in 10 apartment buildings, each with a $5 \mathrm{~kW}_{\text {el }}$ CHP miniplant. The overall power demand is $360 \mathrm{MWh}$ p.a. plus $1920 \mathrm{MWh}$ thermal demand. The reference case without cogeneration shows an average value of $52,06 € / \mathrm{MWh}$ for bought electricity. The price variable switching threshold causes that the price spread between imported and exported grid power adjusts in favour of the micro cogeneration operating customer. However, the total costs of energy supply 
including the expenses for natural gas vary only slightly around $72.500 €$ (reference case $76.343 €$ ). Depending on the operational mode, the price variable heat storage switch gives a benefit of $30-110 €$. This is due to more than 6.000 full load hours which do not allow much load shifting.

Table 1: $\quad$ Imported $(+)$ and exported (-) electricity per year.

\begin{tabular}{|r|c|c|c|c|r|}
\hline \multicolumn{2}{|c|}{ variable storage limits } & \multicolumn{3}{c|}{ fixed storage limits } \\
\hline energy & amount & price & energy & amount & price \\
\hline$[\mathrm{MWh}]$ & {$[€]$} & {$[€ / \mathrm{MWh}]$} & {$[\mathrm{MWh}]$} & {$[€]$} & {$[€ / \mathrm{MWh}]$} \\
\hline \multicolumn{6}{|c|}{ grid driven } \\
\hline$+47,5$ & +2328 & 49,02 & $+44,5$ & +2276 & 51,15 \\
\hline$-22,4$ & -1166 & 52,09 & $-22,3$ & -1253 & 47,65 \\
\hline \multicolumn{7}{|c|}{ power driven } \\
\hline$+46,3$ & +2324 & 50,22 & $+44,3$ & +2276 & 51,38 \\
\hline$-20,6$ & -1060 & 51,38 & $-23,7$ & -1132 & 47,78 \\
\hline \multicolumn{7}{|c|}{ heat driven } \\
\hline$+76,6$ & +3489 & 45,55 & $+75,9$ & +3488 & 45,98 \\
\hline$-33,1$ & -1557 & 47,05 & $-32,9$ & -1516 & 46,10 \\
\hline
\end{tabular}

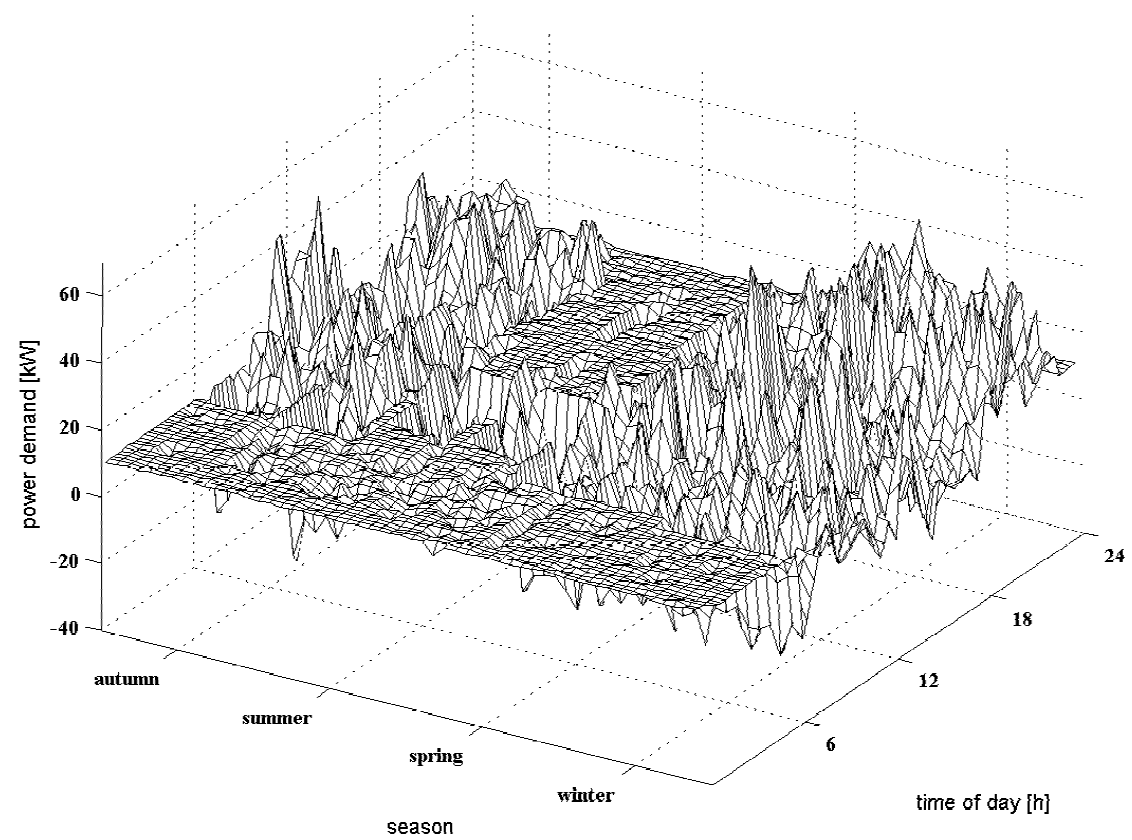

Figure 6: Power demand of a CHP equipped settlement (80 households) in grid driven mode combined with a feed-in tariff profile. 


\section{Future prospects}

Large scale virtual power plants at the low voltage level could result from the heating technology's innovation cycle. Compared with the life cycle of low temperature heating systems and condensing boilers, the $\mu \mathrm{CHP}$-block stands a chance of being the dominant domestic heat source in two decades Colijn [7]. Figure 6 illustrates the aggregate electric load of the simulated settlement described above. A static, but daytime variable price profile has been implemented. During times of high heat demand, the CHP-modules run at full load and the curve is dominated by the stochastic power demand. In the summer, the feed-in occurs in the late morning hours, when the rising price expands the usable storage volume. The flat areas of the matrix show the grid driven mode.

The residential area substitutes (e.g. coal based) medium load power by natural gas, as the feed-in primarily occurs during the day. Primary energy consumption is reduced by $10-15 \%$, with a modern coal fired power plant $\left(\eta_{\mathrm{el}}=\right.$ $45 \%)$ as a reference. In Germany, the market for domestic space heating and hot water is about 2400 Petajoule BMWi [8]. Combined with cogeneration at available efficiencies $\eta_{\mathrm{el}}=15 \%$ this could generate $100 \mathrm{TWh}$.

Thus, fostering $\mu \mathrm{CHP}$ is a twofold approach to $\mathrm{CO}_{2}$ reduction: efficiency improvement plus fuel shift. Fixed feed-in tariffs have shown effectiveness in the stimulation of the renewable energy market Held et al [9]. This instrument has the potential to accelerate the technology specific innovation system and to generate a mass market for magic boilers as well.

\section{References}

[1] Arndt, U. et al., Energiewirtschaftliche Bewertung dezentraler KWKSysteme für die Hausenergieversorgung. Energie und Management Verlagsgesellschaft mbH: Herrsching, 2004.

[2] Schwab, A., Elektroenergiesysteme. Springer: Berlin, 2006.

[3] Pehnt, M. et al., Micro Cogeneration. Springer: Berlin, 2006.

[4] Mauch, K.: Power Electronic Interfaces for DER. First International Conference on the Integration of Renewable Energy Sources and Distributed Energy Resources, Ostbayerisches Technologie-Transfer-Inst.: Regensburg, 2004.

[5] Bühner, V., Virtuelle Kraftwerke in der praktischen Anwendung - Energien effizient bündeln. Smart Grids - der Beitrag virtueller Kraftwerke zur nachhaltigen Energieversorgung, VWEW: Frankfurt am Main, 2006 \& personal communication.

[6] Buchholz, B., Virtuelles Kraftwerk im Praxistest: Ergebnisse aus der Wohnsiedlung "Am Steinweg". Smart Grids - der Beitrag virtueller Kraftwerke zur nachhaltigen Energieversorgung, VWEW: Frankfurt am Main, 2006 \& personal communication.

[7] Colijn, M., MicroCHP International - Strategien in den Niederlanden und in Großbritannien. KWK-konkret: Kraftwerk im Haus - Chancen und Hemmnisse der Mikro-KWK, Berliner Energietage: Berlin, 2004. 
34 Energy and Sustainability

[8] Bundesministerium für Wirtschaft und Technologie, Energiedaten Nationale und Internationale Entwicklung, BMWi: Berlin, 2006.

[9] Held, A. et al, Evaluation of renewable promotion schemes in the European Electricity market. Current development of Green IPPs: Experiences, Challenges, and Strategies, Universitätsverlag Karlsruhe: Karlsruhe, 2005. 